\title{
DIE KULTUURTAAK VAN DIE SKOOL: OPVOEDING TOT BESKAWINGSMONDIGHEID: 'N CHRISTELIK - WETENSKAPLIKE PERSPEKTIEF. DEEL 1
}

\author{
P.G. Schoeman \\ Departement Wysgerige Pedagogiek en Andragogiek \\ Universiteit van die Oranje-Vrystaat \\ BLOEMFONTEIN
}

\begin{abstract}
Even to the casual observer, it is apparent that there is a definite relationship between the education of the child, his cultural heritage, and the cultural environment within which the educational enterprise is set in motion. The status and position of culture as educational objective, however, has become problematic, especially in a country like South Africa where cultural differences have for many decades provided the foundation for serious disparities in the provision of education to its citizens. Where the RSA is apparently on the verge of radical and far-reaching change regarding its future educational policies, the following questions have to be addressed: Can culture be regarded as a regulating principle (like for instance the Christian) which must (co-)determine the spirit and direction of education? Or is culture merely the necessary facilitator which provides for adequate and tension free education, regardless of the noture of the society in which education manifests itself? The current demand to promptly and irrevocably expunge a system of fragmented and therefore repressive and unjust educational control (which is undeniably founded on the cultural differences which exist in this country), by implication also relativizes the role culture has to ploy in the education of the child. A fundamental reconsidcration of the relationship between education and culture, as well as of the question as to whether cultural development can still legitimately be incorporated as a part of education which is no longer to be tom asunder solely on account of political strategies, is therefore essential at this stage. It should be ascertained what the impact of culture is on education in general, and whether and to what extent a concept like cultural motwring can function as an acceptable and legitimate educational objective for a non-repressive, non-racial but multi-cultural South African society.
\end{abstract}

After an initial survey of the relationship between education and culture, an attempt is made to investigate the nature and possibilities of certain cultural principles which - in an analogical way allow for the nomative expansion of all pre-cultural aventes of human life. In this regard, norms like cultural distinction, cultural solidarity, cultural development, elc. are to be considered.

\section{MOTIVERING}

Dat daar 'n direkte verband bestaan tussen opvoeding en die kultuur waarbinne dit plaasvind, sal moeilik ontken kan word. Kultuur bied immers steeds die konteks waarbinne opgevoed word (vgl. byvoorbeeld Dekker \& van Schalkwyk, 1989:3, 7-8; Lowisch, 1989:24, 51 e.v., veral 60-62). Aangesien dit egter sélf aan beginsels onder- 
worpe is, ontstaan die vraag of die kulturele - soos byvoorbeeld die geval is met die Christelike - opgevat mag word as (en selfs verhef word tot) 'n (vermeend)-regulatiewe beginsel wat bepalend geag word vir die gees en rigting van opvoeding oor die algemeen? Moet kultuur nie veel eerder gesien word as fasiliteerder wat die vlot en spanningsvrye verloop van die opvoedingsonderneming, ongeag die aard van die samelewing waarin dit verskyn, waarborg uie (vgl. Dekker \& van Schalkwyk, 1989:7)? Is die ideaal van kultuuropvoeding, in die lig van die radikale veranderinge wat onderwys in die RSA voor die deur staan, nog enigsins regverdigbaar?

Tans word die spoedige en algehele opskorting geëis van die gangbare onderdrukkende stelsel van versnipperde onderwysbeheer wat opsigtelik op kulturele verskille tussen die mense van hierdie land berus. Hiermee word egter tegelyk ook die funderende rol wat kultuur ten opsigte van opvoeding vervul, gerelativeer en selfs bevraagteken. Herbesinning oor die presiese verband tussen kultuur en opvoeding skyn derhalwe noodsaaklik te wees. Daar behoort veral nagedink te word oor die wyse waarop kultuur die opvoedingspraktyk beïnvloed, en daar moet vasgestel word of iets soos opvoeding tot beskawingsmondigheid, of kultuurontwikkeling van die opvoedeling op skool, nog enigsins 'n wettige en haalbare opvoedingsdoelstelling vir 'n multikulturele SuidAfrikaanse opset kan wees.

\section{DIE VERBAND TUSSEN KULTUUR EN OPVOEDING}

Kultuur kan breedweg gedefinieer word as die geheelproduk van die vormingsmag van ' $n$ bepaalde groep mense op 'n bepaalde stadium in die geskiedenis (vgl. Schoeman, 1982:147-153). Die feit dat die mens oor vormingsmag beskik, beteken egter nie dat hy onthef is van 'n besondere verantwoordelikheid ten opsigte van die wyse waarop hy hierdie vormingsmag aanwend nie (vgl. Dooyeweerd, 1955:235; ook Van Brummelen, 1972:74). Dít geld nie net die relatiewe en relasionele ampsgesag (mag) wat hy oor persone mag hê nie, maar juis ook sy vrye beskikkingsmag oor (natuur-)dinge (vgl. Schouls, 1972:12,13-15). En omdat kultuurnorme en nie natuurwette nie, op alle kultuuraktiwiteite van die mens, vanaf die logiese tot die pistiese, van toepassing is, mag kultuur nooit reduksionisties opgevat word as of dit eksklusief beperk sou wees tot een of hoogstens enkele fasette van die lewe van die mens (gewoonlik die volkse/ nasionale) nie. Inteendeel, dit moet onderken word as betrokke op die ganse normatiewe dimensie van menswees.

Omdat dit tot die aard van kultuurgemeenskappe behoort om 'n besondere kultuurerfenis of -nalatenskap aan elke opkomende geslag oor te dra, is kultuurverruiming en -verdieping, asook kultuuroordrag, steeds 'n inherente deel van die opvoedingspogings van alle gemeenskappe (vgl. Lowisch, 1989:ix,4). En aangesien die mens se vermoë tot 
kultuurvorming 'n normatiewe aangeleentheid is (vgl. Schuurman, 1975:30-31), verkry die opgawe van opvoedingsinstansies (veral ouerhuis en skool) dan ook die nodige reliêf betreffende die opvoeding van die onmondige persoon tot die normgehoorsame volvoering van sy kultuurtaak.

In hierdie studie word die term opvoeding aangewend as 'n oorkoepelende en allesinsluitende begrip wat, vanweë die besondere gestruktureerdheid daarvan, essensieel ongekwalifiseerd moet wees (vgl. Strauss, 1978:301; Schoeman, 1983:96-99; ibid., 1987:358-437). In hierdie sin omsluit die term opvoeding inderdaad alle besondere vergestaltinge van die doelbewuste bemoeienis van mondige met onmondige persone, soos aangetref word in die onderskeie opvoedingsinstansies waaronder huisgesin, skool, kerk en so meer. Dít beteken dat die oorkoepelende doel van opvoeding, vanweë die uiters soepel aard daarvan, nie op eenduidige wyse gekwalifiseer kan word as byvoorbeeld analities, kultureel, linguaal, sosiaal, ekonomies, esteties, juridies, eties of godsdienstig nie.

Wat die besondere doel van opvoeding betref is die saak egter heeltemal anders gesteld. Die besondere doel van opvoeding hang telkens op onverbreeklike wyse saam met die struktuur van die bepaalde samelewingsverband waarbinne 'n ooreenstemmende soort opvoeding plaasvind. Om hierdie rede kan sinvol onderskei word tussen die besondere aard van byvoorbeeld gesinsopvoeding wat, ten opsigte van alle fasette daarvan, gekenmerk word deur die onderlinge liefde wat enersyds tussen ouers en kinders bestaan, en andersyds onderwysende (dit wil sê skool-tipiese) opvoeding soos wat dit binne skoolverband voorkom (vgl. Dooyeweerd, 1957:262-266; Schoeman, 1987:427-428).

\section{BESKAWINGSONTWIKKELINGSNORME IN FUNDERENDE TYDSRIGTING}

\subsection{Die beginsel van kultuuronderskeiding}

Wanneer besin word oor die kultuurverdieping van die voorhistoriese bestaanwyses van die opvoedeling, is die eerste aspek wat in funderende tydsrigting vanaf die kultuurhistoriese ontmoet word, die logiese. Dít beteken dat die kultuurhistoriese direk gefundeer is in 'n logies-analitiese substruktuur (Dooyeweerd, 1955:229 e.v.), en hierdie feit laat dan ook die logiese analogie binne die struktuur van die kultuur-historiese in die blikveld tree. Die belangrikheid van die insig dat kultuurvorming op 'n logies-analitiese onderbou berus, verdiep sodra bedink word dat slegs wesens met 'n logies-analitiese besef enigsins as kultuursubjekte, dit wil sê vormers van kultuur beskou kan word (Dooyeweerd, 1955: 230, 258). Omdat die logiese dan funderend vir 
Die kultuurtaak van die skool: deel I

die modale struktuur van die kulturele is, maak dit, in die vorm van historiese teë. spraak, die grondslag uit van elke vorm van kultuuronderskeiding. Hierdie onderskeiding berus weliswaar op die logiese beginsel van teëspraak, maar besit in hierdie geval essensieel kultuur-historiese betekenis.

Kultuuronderskeiding word dan gemanifesteer as 'n verantwoordelike, verantwoordbare en geregverdigde kritiese ingesteldheid teenoor alle aspekte van die eie kultuur en die eie tradisie (Strauss, 1969:71; Dooyeweerd, 1955:231, vgl. ook Löwisch, 1989:46). Immers, historiese ervaring is geensins moontlik sonder inplisiete of eksplisiete bewussyn van die historiese identiteit van die groot verskeidenheid van kultuurgebeure nie. Die onderskeiding van gebeure as enersyds histories betekenisvol al dan nie, en andersyds as histories norrnatief of anti-normatief andersyds kan slegs op logies-analitiese gronde deur die mens gemaak word (vgl. Dooyeweerd, 1955:232, 236-237; Strauss, 1969:71). Die identifisering en negering van die ou hout of afgestorwe elemente, soos onder meer die ossewa-kultuur van die Afrikaner (vgl. Strauss, 1978: 72) en sekere heilige koeie, waaronder byvoorbeeld die kapitalistiese idee van vooruitgang ten alle koste (ekonomies, wetenskaplik, tegnies - vergelyk Lowisch, 1989:5-10), beteken in enige kultuur 'n wegbreek van wat breedweg as reaksionêre konserwatisme bestempel kan word. Dergelike aksies berus opsigtelik op die grondslag van analitiese onderskeiding sonder om self van analitiese aard te wees. Dít is so omdat hulle deur en deur bepaal word deur die kern-sin van die kultuur-historiese aspek naamlik dié van beheersende vorming (of kultuurvorming), wat dan ook weer eens die normatiewe aard van menslike kultuurarbeid in fokus bring (Dooyeweerd, 1955:235; Strauss, 1978:72). Inderdaad, dit is onmoontlik om enige kontinuîteit in kultuurontwikkeling te boekstaaf sonder dat onderskei word tussen dit wat in ooreenstemming daarmee (dit wil sê kultuur-histories normatief) is, en wat nie (vgl. Dooyeweerd, 1955:236).

Van groot belang in verband met kultuurontsluiting is verder die verskynsel dat vanaf die logiese tot die pistiese aspek, dit wil se in 'n transendentale tydsrigting, alle modale wette slegs gegee is as regulatiewe beginsels wat hoegenaamd nie aan die feitlike of subjeksy van die werklikheid van toepassing gemaak kan word sonder behoorlike rasionele oorweging en logiese onderskeiding deur 'n menslike kultuurvormer nie (vgl. Strauss, 1978: 74). Transendentale tydsrigting vanaf die historiese aspek benodig alle normatiewe beginpunte, vrye vormgewing of toepassing (Strauss, 1978:64-65), selfs al is die modale sin daarvan nog nie ontsluit nie. Deur middel van vrye vormgewing as die beheersende tussenkoms van die mens as bevoegde kultuurvormer, word hierdie (latente) begin(-sel)-punte vir normatiewe handelinge, patent-gemaakte, dit wil sê tot positiewe geldende gebringde norme wat in mindere of meerdere mate bydra tot die algemene gang van kultuurontwikkeling. En vir hierdie immer veranderende vormingstaak (of kultuurmandaat) van die mens van die toekoms moet ook die skool opvoed (vgl. Van Brummelen, 1972:73-74). 
Indien die kind dan opgevoed moet word tot identifisering van homself met elke gedifferensieerde samelewingsvorm binne die kultuurgemeenskap waarvan hy deel is, beteken dit dat hy deurgaans soveel moontlik kennis aangaande en insig in die normatiewe gestruktureerdheid van die onderskeie instansies wat hy in die samelewing gaan ontmoet, sal moet verwerf. Langs hierdie weg sal hy hopelik daartoe in staat wees om viteindelik anti-normatiwiteit in die samelewing te kan identifiseer, asook om realistiese alternatiewe aan te dui op weg na die vestiging van 'n Christelike kultuur in die ware sin van die woord (vgl. Van Brummelen, 1972:75). Hy moet derhalwe enersyds waardering kan betuig vir die doel en strewe van die onderskeie samelewingsvorme, dog andersyds steeds krities-waarderend daarteenoor staan. Slegs indien hy oor genoegsame kennis en insig in hierdie verband beskik, sal hy ook die bevoegdheid besit om met wettige gesag menings daaroor uit te spreek in die vorm van welgefundeerde kultuurkritiek.

\section{Die beginsel van kultuursolidariteit}

Die verband tussen die historiese en die logiese kom duidelik na vore in die verweefdheid van die normatiewe beginsel aan die een kant, en die menslike vormende wil aan die ander kant. Die feit dat daar in verband met kultuurvorming sprake is van 'n vrye, vormende wil, vereis kritiese rekenskap van alles wat kosmies-vroeër as die logiese geleë is, en in hierdie geval eerstens die psigiese analogie wat binne die struktuur van die kultuur-historiese verskyn (Dooyeweerd, 1955:243, 244).

Die vrye, vormende (dit wil sê histories-formatiewe) wil waaroor kultuurvormers beskik, verwys opsigtelik na die modale sin van die psigiese aspek, en meer besonderlik na psigiese funksies soos wilsdaad, vrye wil, emosionele strewe, begeerte en so meer (Dooyeweerd, 1955:244). Histories-formatiewe wil kan egter vanselfsprekend nie vereenselwig word met strewe en begeerte soos ons dit teëkom in die geval van die psigiese bestaanswyse van die mens nie. Die histories-formatiewe wil waarvan hier sprake is, verwys in hoofsaak na 'n essensiële moment in die historiese beheersingsmag van die mens. Dit konkretiseer, positiveer, verruim en verdiep die modale ontwikkelingsbeginsels van die historiese wetskring in ál die tipiese totaalstrukture van die onderskeie kultuursfere (Dooyeweerd, 1955: 244).

In hierdie geval is daar dan sprake van magsvorming, nie net oor kultuurobjekte nie, maar inderdaad ook - weliswaar relatief en relasioneel - oor menslike subjekte. En hierdie magsvorming oor persone gryp terug op die emosionele ervaring van ondergeskiktheid deur bepaalde persone in die teenwoordigheid van persoonlikhede van meerdere statuur (Dooyeweerd, 1955:247). Waar daar egter wél sprake is van mag oor persone, moet daarop gewys word dat hierdie mag steeds normatief opgeneem en ge- 
konsolideer is binne die sfeer van kultuurvorme wat die willekeur van individuele persone te bowe gaan (vgl. Schouls, 1972:13-14; Strauss, 1969:73).

Historiese mag is gevolglik geen ar.ti-normatiewe sinfiguur nie, maar besit opsigtelik 'n normatiewe karakter wat geopenbaar word in die vorm van normgehoorsame beheersende vormgewing (Dooyeweerd, 1055:246; Strauss, 1978:65). Die besitter van mag beskik met ander woorde nie daaroor asof dit sy "persoonlike eiendom" is wat hy na willekeur kan aanwend nie. Gepaard met hierdie mag gaan die normatiewe opgawe dat dit moet bydra tot die positiewe ontwikkeling van die menslike beskawing. Om hierdie rede lewer menslike beheersende vormingsmag dan steeds, in gehoorsaamheid aan bepaalde bowe-individuele en bowe-arbitrêre Godgegewe beginsels, 'n bydrae tot of die beskerming, of die verdere uitbouing (vernuwing) van die bestaande kultuur (Dooyeweerd, 1955:247-248).

In terme van wat hierbo aan die orde gestel is, is dit duidelik dat die skool 'n besondere opdrag het in die opvoeding van die kind tot 'n kritiese solidêr-wees met die eie kultuur, tradisie, volk, gewoontes, taal, gemeenskap, sedes, geloof en so meer. Inderdaad, slegs indien aan hierdie eis voldoen word, kan gevorder word tot die bereiking van wat ons breedweg kan bestempel as kritiese solidariteit van die individuele persoon met die kultuur waarbinne hy leef. Met verwysing na die voorafgaande gedeeltes waar reeds sydelings gewag gemaak is van kultuurkritiek, spreek dit vanself dat kritiek, as sodanig, meestal nie die gewenste indruk maak indien die kritikus nie self solider is met dit wat krities-waarderend bevraagteken word nie. Wanneer kritiek vanuit die oord van medestanders kom, dit wil sê vanaf diegene van wie die goeie en eerlike bedoelings nooit betwyfel kan word nie, bestaan daar sekerlik 'n veel groter moontlikheid dat eerlike en goedbedoelde kultuurkritiek menings kan laat verander. Kom kultuurkritiek egter vanuit 'n eksterne en selfs vyandige oord, word dit te maklik ongeag die moontlike meriete en geldigheid daarvan - as onaanvaarbare inmenging van onsimpatieke buitestanders afgemaak. Om hierdie rede is dit nodig om tuis, sowel as op skool, in kultuurverband op te voed vir wat goedskiks as kritiese solidariteit bestempel kan word.

\subsection{Die beginsel van kultuurontwikkeling}

Groei beteken vanselfsprekend lewe, ontwikkeling, vertakking, vermeerdering van funksies, met ander woorde differensiasie met behoud van die geïntegreerde aard van die geheel (vgl. Dooyeweerd, 1955:274-276; Strauss, 1969:72). In hierdie verband kom norme soos kultuurdifferensiasie, kultuurintegrasie en beskawingsontwikkeling (Dooyeweerd, 1955:-178, 193, 196, 201, 232, 241, 242, 259, 260; vgl. ook Strauss, 1965:44; Koole, 1977:52) wat sonder uitsondering biotiese analogieë binne die 
struktuur van die kultuurhistoriese verteenwoordig, in sig. Omdat dit tydens beskawingsontwikkeling gaan om die voortgaande verfynende ontplooiing van volke, van samelewingsvorme en die individualiteit van persone, kan differensiasie breedweg omskryf word as 'n normatiewe beginsel wat voorsiening maak vir die eiesoortige ontplooiing en ontwikkeling van tradisie, taal, gemeenskapslewe en -ordening, bedryfslewe, staat, huisgesin, kerk, dog ook van skool, universiteit en so meer.

\subsection{Differensiasie}

Differensiasie binne opvoedingsverband impliseer ook dat gevoeligheid geopenbaar sal word vir die stand van sake dat bepaalde opvoedingsfunksies op minder of meer suksesvolle wyse deur die onderskeie kultuurinstansies vervul kan word (vgl. Koole, 1977:52). So blyk dit byvoorbeeld dat indien ouers sou weier om die opvoedingstaak van die skool te erken en daarop sou aandring om ook alle vorme van onderwysende opvoeding, dít waarvoor die skool - vanweë sy besondere gestruktureerdheid - juis by uitnemendheid toegerus is, op hulleself te neem, dit sou neerkom op 'n reaksionêre optrede wat remmend, indien nie vernietigend nie, sal inwerk op die algemene kultuurontwikkeling van die kind. Waar primitiewe kulture grootliks ongedifferensieerd is en helder afgebakende bevoegdheidsterreine ten opsigte van die onderskeie (gedifferensieerde) kultuurinstellings (staat, kerk, skool, bedryf en so meer) ontbreek, word die spanningsvrye saambestaan van dergelike relatief outonome kultuurinstellings haas onmoontlik gemaak. Om hierdie rede moet die ideaal van kultuurdifferensiasie, as die praktykwording van die ideaal aangaande onafhanklike en relatief outonome state, kerke, bedrywe, skole, kolleges, universiteite en so meer, reeds op skool by die opvoedeling gevestig word, omdat dit die ideale toestand van 'n behoorlik ontslote en beskaafde gemeenskap verteenwoordig. Hierdie voortgaande differensiasie gaan ook gepaard met die stelselmatige emansipasie van elke individuele lid van die gemeenskap. Immers, gesonde kultuurdifferensiasie impliseer ook die erkenning van die waardigheid en regte van elke individuele menslike persoonlikheid, ongeag geloof, ras, velkleur of wat ook al: elke mens moet uiteindelik, afgesien van sy hegte verbondenheid aan 'n bepaalde gemeenskap van persone, ook ontwikkel tot 'n individuele persoon in sy eie reg, wat binne die groep/gemeenskap waarvan hy deel is, en ondanks sy groepsverantwoordelikhede, terselfdertyd iemand is wat persoonlike aanspreeklikheid kan en moet aanvaar teenoor homself, sy medemens, sy gemeenskap, sy staat, sy kerk, en uiteindelik sy Skepper.

Voorgaande beteken dat elke individuele persoon die vryheid sal besit om volledig en onbelemmerd te mag deelneem aan letterlik álle samelewingsvorme binne 'n gedifferensieerde gemeenskap. Slegs langs hierdie weg is dit die mens beskore om vryuit en tegelyk lidmaat te wees van 'n besondere kerk, lid van 'n bepaalde huisgesin, burger 
van 'n staat, lid van die politieke party van sy keuse, van 'n besigheidsonderneming en so meer. En slegs onder dergelike omstandighede sal dit vir die individuele persoonlikheid binne die gemeenskap moontlik wees om te lewe volgens die struktuurbeginsel van die kerk, die huisgesin, die staat, die sakeonderneming, die sportklub, die kultuurvereniging of wat ook al. Alleen só 'n onbelemmerde vryheid van assosiasie vir elke individuele persoon in die gemeenskap waarborg sy vrye keuse ten opsigte van en onbelemmerde deelname aan byvoorbeeld bepaalde geloofsaktiwiteite (as uitlewing van besondere geloofsoortuigings), die vrye keuse van 'n lewensmaat, van 'n politieke standpunt, van 'n bepaalde beroep, sportdeelname, kultuurbedrywighede en so meer. Met ander woorde, slegs op die grondslag van gedifferensieerde kultuur- en persoonlikheidsontwikkeling kan die opvoedeling vorder na steeds groter betrokkenheid by die volle spektrum van gemeenskapsverhoudinge waarin hy, as beskawingsmondige persoonlikheid uiteindelik met bepaalde opgawes en verantwoordelikhede beklee sal wees (vgl. Greene, 1977:12).

Dieselfde geld op analogiese wyse ook vir die kulturele opvoeding van die kind. Inderdaad, gebrek aan differensiasie van potensialiteite en funksies by die mens skort ook die moontlikheid van volledige kultuurontwikkeling op. Gesonde kultuurontwikkeling op skool is net nie haalbaar indien die beginsel van differensiasie nie tot volle ontplooiing kom nie. In die onderwyspraktyk kom dit daarop neer dat selfs ten opsigte van leerstof gedifferensieer sal word, en wel met betrekking tot leerstofkeuse, dog ook ten opsigte van die gradering, rangskikking en uiteindelike aanbieding daarvan. Langs hierdie weg, so word gehoop, sal die vermocns en funksies van die opvoedeling dermate differensieer dat hy op doeltreffende wyse toegerus kan word om sy kultuurtaak as individuele kultuurvormer in eie reg binne steeds meer samelewingsvorme op normgehoorsame wyse te volvoer, en dat hy uiteindelik as normatief-ontslote persoonlikheid op alle lewensterreine sal kan omgaan met alle objektiewe kultuurgoedere soos vereis deur ons ingewikkelde moderne samelewing (vgl. Strauss, 1969:70-73, ook 233e.v.).

Verder is differensiasie ten opsigte van letterlik alle moontlike persoonlikheidseienskappe, behoeftes, aanleg, aansprake, en so meer van individuele leerlinge 'n belangrike funksie van die skool (vgl. Greene, 1977:11). Die blote feit dat die grondslag van die skool te vinde is in die kultuurhistoriese agtergrond van gemeenskappe, dui daarop dat gesonde differensiasiemoontlikhede daarin ingebou sal word, nie net ten opsigte van die kultuur-historiese nie, dog veral ook ten opsigte van die lewens- en wêreldbeskoulike, religieuse, en ander verskille wat tussen onderskeie groeperinge binne heterogene kultuurgemeenskappe mag bestaan. Erkenning van die verskeidenheidsbeginsel bring mee dat die onvervreembare reg van persone sowel as kultuurgroepe (desverkiesend en sonder eksterne dwang) op onderwys in die eie taal, asook in 'n kontinue lyn met ' $n$ kulturele, religieuse, lewensbeskoulike, ensovoorts, erfenis gehandhaaf word tot voordeel van alle betrokke partye. Die haalbaarheid of ekonomiese regverdigbaar- 
heid van eise in hierdie verband moet egter ook deurgaans verreken word. Wat hier van besondere belang is, is dat kultuurgebonde onderwys/ opleiding nie, byvoorbeeld van owerheidsweě, op persone of groepe afgedwing mag word nie, aangesien dit in die laaste ontleding die prerogatief van persone (asook groepe) bly om die kultuurgrondslag van hulle opvoeding sélf te kies.

\section{VOORSKOU}

In 'n volgende artikel sal, teen die agtergrond van wat hier met betrekking tot beskawingsontwikkelingsnorme aangemerk is, gefokus word op enkele oorblywende beskawingsontwikkelingsnorme wat in 'n funderende tydsrigting vanaf die historiese geleë is. Daar sal aandag gegee word aan die integrasie-komponent van die beginsel van kultuurontwikkeling, en daarna sal die aandag toegespits word op kultuurbeginsels soos kultuurdinamiek, kultuurvoortgang, kultuurkonteks en kultuureenheid.

\section{BIBLIOGRAFIE}

DEKKER, E. \& VAN SCHALKWYK, OJ. 1989. Moderne onderwysstelsels, Durban : Butterworths. DOOYEWEERD, H. 1955. A new critique of theoretical thought. Vol. Il. Amsterdam : Paris.

DOOYEWEERD, H. 1957. A new critique of theoretical thought. Vol. III. Amsterdam : Paris

GREENE, A.E. 1977 . Norms and objectives for Christian education. (In Steensma, GJ. \& Van Brummelen, H.W. Shaping school curriculum. Terre Haute : Signal. p. 9-14.)

KOOLE, R. 1972. The social studies. (In Steensma, G.J. \& Van Brummelen, H.W. Shaping school curriculum. Terre Haute : Signal. p. 50-61.)

LoWISCH, D-J. 1989. Kultur und Pảdagogik. Darmstadt : Wissenschaftliche Buchgesellschaft.

SCHOEMAN, P.G. 1980. An introduction to a philosophy of education. Durban : Butterworths.

SCHOEMAN, P.G. 1982. Culture, society and education - the quest for alternatives. South African Joumal of Education, 2:147-153.

SCHOEMAN, P.G. 1983. Wysgerige Pedagogiek. Bloemfontein : Sacum.

SCHOEMAN, P.G. 1987. Metavrae van ' $\mathrm{a}$ agologicse vakfilosofie: transendente en transendentale aprioriet. Ongepub. D. Phil.-proefskrif. Bloemfontein : UOVS

SCHOULS, PA. 1972. Insight, authority and power. Toronto : Wedge.

SCHUURMAN, E. 1975. Na-denken over de technisch-wetenschappelijke kultuur. Ongepubliseerde Intreerede, Technische Hogeschool, Delft.

STEENSMA, G.J. \& VAN BRUMMELEN, H.W. 1977. Shaping schoolcurriculum. Terre Haute : Signal.

STRAUSS, D.F.M. 1969. Wysbegeerte en vakwetenskap. Bloemfontein : Sacum.

STRAUSS, D.F.M. 1978. Inleiding tot dic kosmologie. Bloemfontein : Sacum.

VAN BRUMMELEN, H. 1972. Towards a radical break with the Public School curriculum. (In Vriend, J. ned. To prod the slumbering giant. Toronto : Wedge. p. 69-92.)

VRIEND, J. red. 1972. To prod the slumbering giant. Toronto : Wedge. 
